\title{
MESOPOTAMIAN RELIGIOUS SYNCRETISM ${ }^{1}$
}

\author{
Simon J. Sherwin
}

This thesis attempts to examine the question of syncretism, more particularly the merging of deities and their functions, in the light of the political and historical situation in Mesopotamia in the 3rd and 2nd millennia BC. This is a text-based project and both Sumerian and Akkadian sources have been used, including god lists, hymns and prayers, narrative texts and historical documents. These come from a variety of geographical locations, including Ugarit, Ebla, Emar and Mari as well as sites within Mesopotamia proper.

An introductory chapter sets out to define terms, in particular what is meant by the elusive word 'syncretism', along with other terms as 'equation' and 'identification', which are employed time and again throughout the investigation. This chapter also seeks to deal with general problems associated with the sources, namely the provenance, geographical spread and dating of texts, and to give an outline of Mesopotamian concepts of the divine, in particular the association of deities with certain cities, divine hierarchy and relationships, and the idea of individual portfolios.

The bulk of the thesis divides into two: the first part is a discussion of the sources, the second, case studies. The sources are treated in the order given above, each comprising a separate chapter (Chapters 2 to 5). Each source type is examined and the subcategories of the source type analysed to determine the value to the investigation of information contained in different texts. A further objective is to ascertain whether certain genres are more applicable than others to a study of this nature.

To take hymns and prayers for example, there are a large number available both in Akkadian and Sumerian, only a minority of which are overtly syncretistic (i.e. expressly equate different deities, either in whole or in part). Of the remainder some can be immediately ruled

1 S.J. Sherwin, Mesopotamian Religious Syncretism: The Interaction of Religion and Politics in the 3rd and 2nd Millennia BC (unpublished Ph.D. thesis, University of Cambridge, 1999); supervisor Professor J.N. Postgate. 
out for the topic under consideration, namely those that do not mention any deity by name (self-praise of kings, or prayers to unnamed personal gods). Others which only mention deities incidentally are also of little value in this study. This still leaves a considerable body of texts which may or may not be of any use. I therefore examined the different genres of text to see whether some were more likely than others to yield relevant material. This served to limit the corpus still further. It may be noted that prayers with a hymnic element are likely to be conservative in content: they invoke deities on the basis of their existing portfolio and characteristics; their aim is not to invent a new theology. This is not necessarily the case with the hymns, which may reflect conventional ideas but may also be, in the desire to extol a particular deity, rather an imaginative exercise on the part of the poet. There is therefore a need for caution and this is acknowledged.

As far as narrative texts are concerned, myths in particular, there are added complications which I had to address. Various schools of interpretation have arisen over the years which can serve to cloud the issue; the tendency to assume a 'nature-myth' origin of some texts, or an astrological or historical background colours the interpretation or explanation of the story. While there are undoubted merits in the different approaches it has led scholars in the past to make assertions that are untenable. Despite this, narrative texts are perhaps one of the richest sources for this topic, since they relate changes and developments especially in the divine world.

Within the chapter on historical documents there is an outline of the main historical and political events during the period in question which one might expect to be of importance in terms of religious development.

The case studies are those of Ninurta and Ningirsu, and the 'national' gods, Enlil, Dagan, Ašsur and Marduk. With Ninurta and Ningirsu I examine their roles and relationships with other deities to determine first of all that two distinct personae are being combined and then to chart the course of religious development.

Possibly of more interest to biblical scholars, however is the consideration of the 'national' gods. In this chapter I start with a description of the role and function of Enlil followed by a diachronic investigation of each of the other three deities in turn. This was necessary since it is with Enlil that the others are equated, and a clarification of his character and portfolio is crucial to understanding 
the basis upon which such an equation is made. The evidence for and the process by which this occurred is therefore outlined.

It is noticeable that while Dagan, Ašsur and Marduk were all identified with Enlil for the same reason, namely the position which he held in the pantheon and the role he played in the political affairs of Sumer and Akkad, there are significant differences in the ways in which this is expressed, and the extent to which the identification gained acceptance in the country as a whole. The reasons for this are touched on in chapter 7, but enlarged upon in the concluding chapter.

As a result of my investigation into Dagan, it has been possible to correct some past misunderstandings on the part of biblical scholars. The character and role of Enlil supports neither an underworld role nor a storm-god character for Dagan. Whatever other arguments there may be to suggest this, his association with Enlil cannot be invoked as corroboratory evidence. Apart from the fact that speculations about such a character and role for Enlil are without foundation, it is clear from an examination of the available evidence that as with the others, so Dagan is identified with Enlil on the basis of the political role which he played in his own territory. He was to the west what Enlil was to Mesopotamia proper.

The concluding chapter seeks to assess the results gained from Chapters 6 and 7 and to place them within the political and historical context. 